\title{
DYNAMIC IMPACT WEAR AND IMPACT RESISTANCE OF W-B-C COATINGS
}

\author{
Josef Daniel $^{a, *}$, JAN Grossman ${ }^{a}$, Vilma BurŠíková ${ }^{b}$, \\ Lukáš ZÁbranský $^{b}$, PAvel SoučeK ${ }^{b}$, Saeed Mirzaei ${ }^{b}$, Petr Vašina $^{b}$ \\ ${ }^{a}$ Institute of Scientific Instruments of the Czech Academy of Sciences, Královopolská 147, Brno 612 64, Czech \\ Republic \\ ${ }^{b}$ Masaryk University, Faculty of Science, Department of Physical Electronics, Kotlářská 2, Brno 611 37, Czech \\ Republic \\ * corresponding author: jdaniel@isibrno.cz
}

Abstract. Coated components used in industry are often exposed to repetitive dynamic impact load. The dynamic impact test is a suitable method for the study of thin protective coatings under such conditions. Aim of this paper is to describe the method of dynamic impact testing and the novel concepts of evaluation of the impact test results, such as the impact resistance and the impact deformation rate. All of the presented results were obtained by testing two $\mathrm{W}$-B-C coatings with different $\mathrm{C} / \mathrm{W}$ ratio. Different impact test results are discussed with respect to the coatings microstructure, the chemical and phase composition, and the mechanical properties. It is shown that coating adhesion to the HSS substrate played a crucial role in the coatings' impact lifetime.

KEYWORDs: Boron carbide, fracture resistance, impact resistance, impact wear, W-B-C.

\section{INTRODUCTION}

Industrially used components coated with protective coatings are often exposed to the external load. In some cases, this load may take the form of repeated dynamic impact. For the investigation of the lifetime of the coated components under this form of load, Knotek et al. developed the method of dynamic impact test in the early 90s [1]. A tungsten carbide ball repeatedly impacted the surface of the specimen. The load force of the ball was well-defined, and the impact frequency was set to a constant value. Coatings' lifetime was evaluated as a maximum number of impacts before coating failure. Knotek also showed that dynamic impact test makes a study of dynamic wear and fatigue behaviour of the whole coating/substrate system possible [1]. In the past decades, the dynamic impact testing was investigated by different researchers. Bouzakis et. al. developed FEM simulation of the elastoplastic deformations of material under dynamic impact load [2] or the inclined dynamic impact test - testing of the coated specimens under various angles of inclination [3]. Engel et. al. proposed a three-stage model of the dependence of the impact crater volume on the total number of impacts based on the coating deformation 4 . Voevodin et. al. investigated the impact lifetime of various Ti-based coatings and discussed it with respect to their chemical composition and hardness [5]. Heinke et. al. used the dynamic impact test as a supplementary method to the evaluation of coatings adhesion [6]. Sobota et. al. investigated the behaviour of DLC coatings under dynamic load in various air humidity [7]. In the past years, the dynamic impact testing also expanded to the field of the thick HVOF sprayed coatings 8 . The aim of this paper is to present some crucial results of dynamic impact testing, important for the investigation of the behavior of the coating under dynamic impact load and for development of the new types of the protective coatings. Novel parameters of impact resistance and impact deformation rate, suitable for better understanding of the behaviour of the coating under repeated impact load, were discussed. Presented results were obtained from two W-B-C coatings with different chemical composition, structure, and mechanical properties.

\section{EXPERIMENTAL}

\subsection{DynAmic IMPACT Tester}

The coatings were tested by a dynamic impact tester developed at the Institute of Scientific Instruments of the Czech Academy of Sciences in Brno. The impact hammer with a lift set at a constant value of 2.4 $\mathrm{mm}$ was electromagnetically driven. Attached to the impact hammer was a ball-shaped cemented tungsten carbide impact indenter with a diameter of $5 \mathrm{~mm}$. The indenter ball was rotated to an unworn contact side before every test. The frequency of impact testing was set to $8 \mathrm{~Hz}$, and the duration of the contact of the ball indenter with the surface was $1.5 \mathrm{~ms}$. The impact testing was carried out with impact loads of 200 N, $400 \mathrm{~N}$ and 600 N. Due to its construction the impact tester is uniquely suitable also for the investigation of the behaviour of the samples under a low number of impacts $(\leq 100)$. Therefore, the number of impacts was in the range from 1 to 500 000. Every test was repeated three times. The depth, 


\begin{tabular}{lllllllll}
\hline $\mathrm{C} / \mathrm{W}$ & $\mathrm{W}($ at. \%) & $\mathrm{C}($ at. \%) & $\mathrm{B}($ at. \%) & $\mathrm{H}(\mathrm{GPa})$ & $\mathrm{E}(\mathrm{GPa})$ & $\mathrm{H} / \mathrm{E}$ & $\mathrm{H}^{3} / \mathrm{E}^{2}$ (GPa) & thick. $(\mu \mathrm{m})$ \\
\hline 0.11 & 63 & 7 & 30 & $28.6 \pm 1.5$ & $500 \pm 12$ & 0.057 & 0.094 & 1.7 \\
0.8 & 40 & 32 & 28 & $23.3 \pm 1.0$ & $400 \pm 12$ & 0.058 & 0.079 & 1.3 \\
\hline
\end{tabular}

TABLE 1. Chemical composition and mechanical properties of the W-B-C coatings.
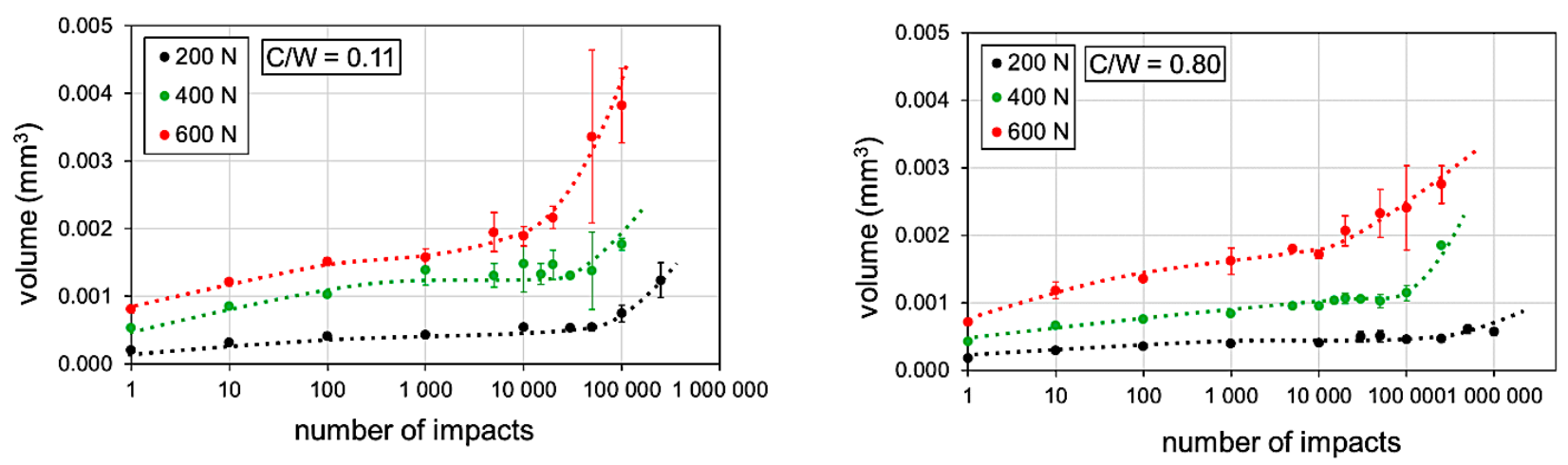

Figure 1. Loading curves of the W-B-C coatings. Dotted lines were added as a visual guide.

the radius and the surface morphology of the impact craters were measured by Talystep profilometer and Lext OLS 3100 confocal microscope.

\subsection{W-B-C COATINGS PREPARATION}

Two W-B-C coatings with different $\mathrm{C} / \mathrm{W}$ ratios were deposited on HSS substrate by magnetron cosputtering of $\mathrm{W}, \mathrm{C}$ and $\mathrm{B}_{4} \mathrm{C}$ targets in $\mathrm{Ar}$ atmosphere. For the detailed description of the coatings' deposition, see Ref. 9].

\section{Results}

\subsection{W-B-C COATINGS COMPOSITION, STRUCTURE AND MECHANICAL PROPERTIES}

The chemical composition and the mechanical properties of the presented W-B-C coatings are summarized in Table 1. Both coatings exhibited an amorphous microstructure. The coating with a higher amount of carbon $(\mathrm{C} / \mathrm{W}=0.80)$ exhibited a higher amount of C-C bonds and B-C bonds and a lower amount of $\mathrm{W}-\mathrm{B}$ bonds. The detailed description of the chemical composition and the microstructure analyses, the evaluation of the mechanical properties and the discussion of the relationship between the microstructure and the mechanical properties can be found in Ref. [9].

\subsection{Results of impaCt Testing}

One of the first results of the dynamic impact test is a loading curve - the dependence of the impact crater volume on the total number of impacts. The loading curves of the studied W-B-C coatings are depicted in Figure 1. The amount of energy supplied from the tester to the tested specimen increased with the increasing number of impacts. This energy caused the deformation of the specimen and thus the formation of the impact crater. As the number of impacts increased further, the supplied energy was dissipated in the form of a continuously increasing internal stress. After reaching some critical number of impacts $\mathrm{n}_{C}$, the tested coating/substrate system was unable to receive more energy from the tester, and the coating failed. The depth and the radius and thus the volume of the impact crater then rapidly increased. These different behaviour modes of the substrate/coating system can be seen on the loading curve as different slopes and thus it is often possible to determine the $\mathrm{n}_{C}$ and therefore the lifetime of the coating under dynamic impact load.

The impact craters in the W-B-C coatings formed after 10000 impacts are depicted in Figure 2. The coating with the $\mathrm{C} / \mathrm{W}$ ratio of 0.11 exhibited impact craters with a higher diameter than the coating with the $\mathrm{C} / \mathrm{W}$ ratio of 0.80 . Moreover, in case of the load of $400 \mathrm{~N}$, this coating exhibited an almost uncovered substrate indicating the first stage of the coating failure. The total coating failure and the uncovered substrate in case of the load of $600 \mathrm{~N}$ for the coating with the $\mathrm{C} / \mathrm{W}$ ratio of 0.11 corresponded to a rapid increase of the slope of the loading curve of this coating depicted in Figure 1. While the coating with the low $\mathrm{C} / \mathrm{W}$ ratio exhibited pronounced chipping cracks in the case of the loads of $400 \mathrm{~N}$ and $600 \mathrm{~N}$, the coating with the higher $\mathrm{C} / \mathrm{W}$ ratio only exhibited small concentered cracks even in case of the highest load of $600 \mathrm{~N}$. The detailed view on the edges of impact craters created with load of $400 \mathrm{~N}$ is depicted in Figure 3

Another parameter describing the behaviour of a coated specimen under the dynamic load is the impact resistance. The impact resistance is defined as follows. The volume of the impact crater created by $\mathrm{N}_{1}$ impacts is denoted as $\mathrm{V}_{1}$ and the volume of the impact crater created by $\mathrm{N}_{2}$, impacts is denoted as $\mathrm{V}_{2}$. An increment of the impact crater volume $\Delta \mathrm{V}=\mathrm{V}_{2}-\mathrm{V}_{1}$. This 


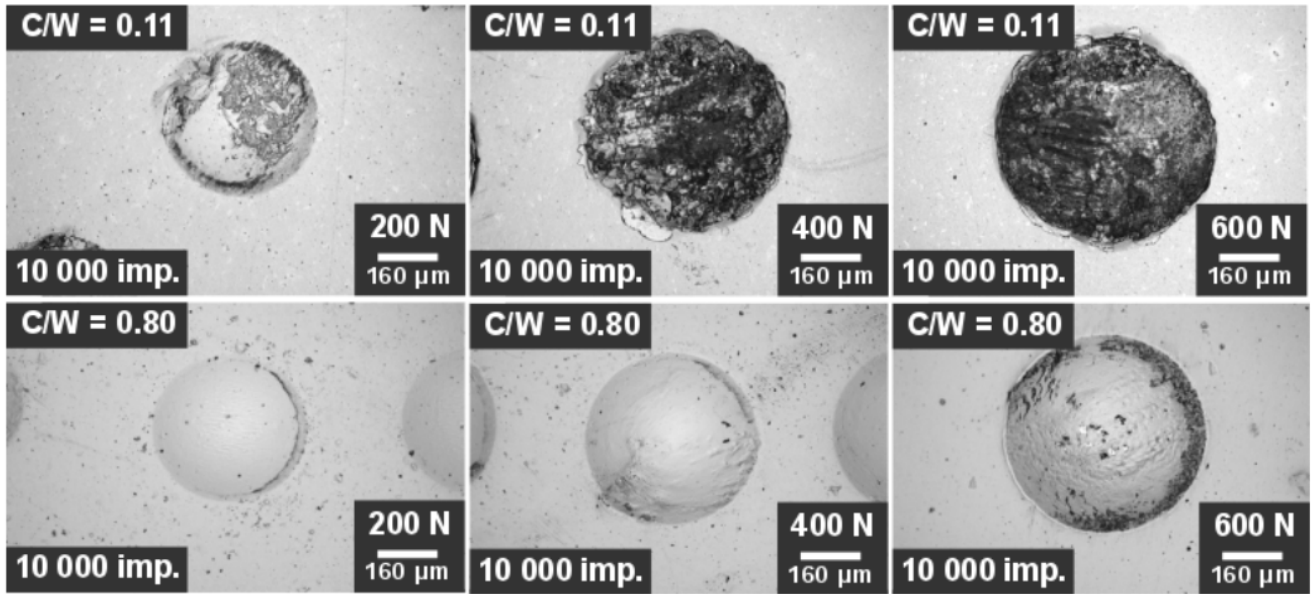

FiguRE 2. Comparison of impact craters created by 10000 impacts.
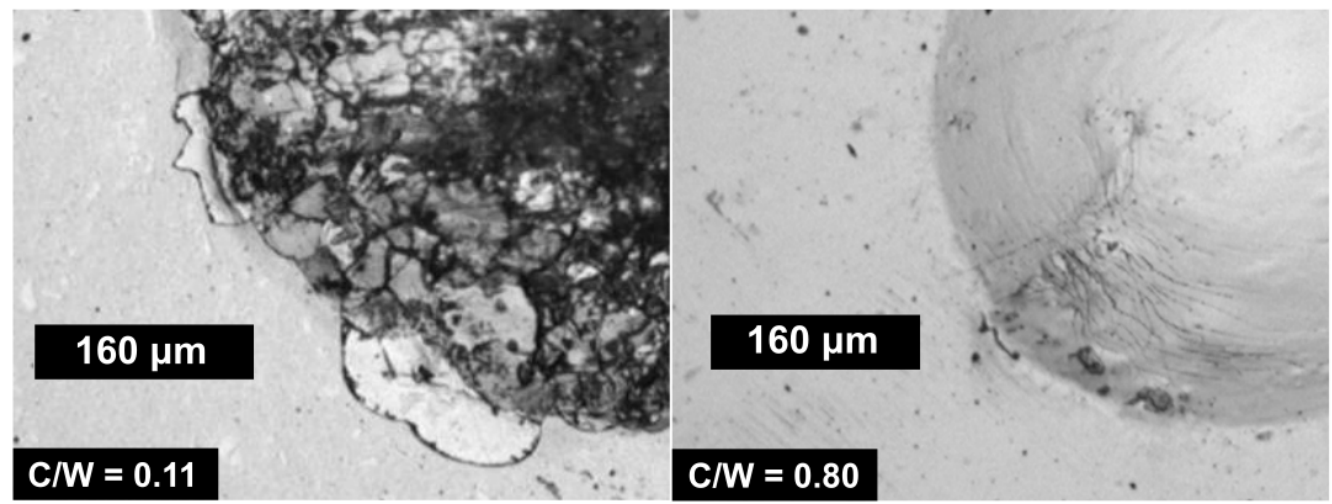

Figure 3. Detail view on the edges of impact craters created with load of $400 \mathrm{~N}$ and 10000 impacts.

increment depends on the number of impacts $\mathrm{N}_{1}$ and $\mathrm{N}_{2}$ 4. Assuming that the increment of $\Delta \mathrm{V}$ is inversely related to the impact resistance of a coating, the impact resistance can be calculated from the volume of impact craters at a given number of impacts. This parameter with the unit of $\left[\mathrm{n} / \mathrm{mm}^{3}\right]$ describes how many impacts (denoted as $\mathrm{n}$ ) are required to create a crater with the volume of $1 \mathrm{~mm}^{3}$.

The impact resistance of the $\mathrm{W}-\mathrm{B}-\mathrm{C}$ coatings is shown in Figure 4 At first, the impact resistance increased with the increasing crater volume due to the elastoplastic deformation of coatings. As the number of impacts increased further, the energy from the tester was dissipated in the form of internal stress and not in the form of the crater deformation. The impact resistance thus reached the highest values. Then, as the coating failed, the volume of the impact crater and also the increment of the volume $\Delta \mathrm{V}$ rapidly increased, and the impact resistance correspondingly rapidly decreased. Therefore, the critical number of impacts $n_{c}$ can also be evaluated using the impact resistance.

The third way of evaluation of the critical number of impacts is from the determination of the deformation rate. Assuming that contact time between the impactor ball and the specimen is the same for every impact, it is possible to calculate the deformation rate as the impact crater volume divided by the total contact time. The deformation rate of the $\mathrm{W}-\mathrm{B}-\mathrm{C}$ coatings is depicted in a log-log scale in Figure 5. The deformation rate linearly decreased as the number of impacts increased. After reaching the critical number of impacts, the impact crater volume rapidly increased and thus deformation rate curve deviated from linearity. The final critical number of impacts was evaluated from the combination of the previously described methods - from the loading curves, the optical investigation of impact craters (uncovered substrate as evidence of the coating failure), the impact resistance and the deformation rates. Figure 6 shows the Woehler-like dependence of the critical number of impacts on the load. The coating with the $\mathrm{C} / \mathrm{W}$ ratio of 0.80 exhibited higher lifetime under dynamic impact at all of the applied loads.

\section{Discussion}

In general, the behaviour of coatings under impact load is closely related to the coating's toughness [2, 5]. Both W-B-C coatings exhibited an amorphous structure and the same $\mathrm{H} / \mathrm{E}$ ratio that is related to the fracture resistance [9]. The coating with the $\mathrm{C} / \mathrm{W}$ ratio of 0.11 exhibited higher hardness and elastic 

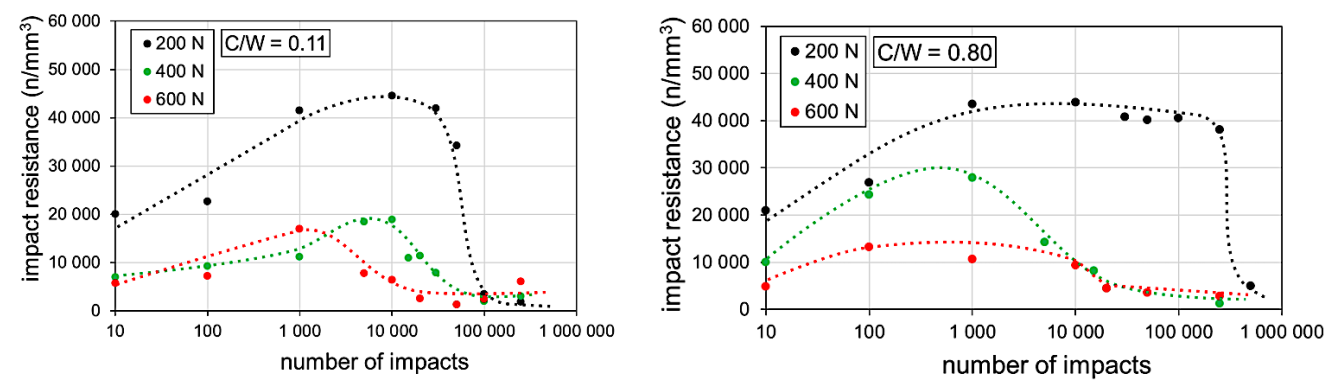

Figure 4. Impact resistance of the W-B-C coatings. Dotted lines were added as a visual guide.
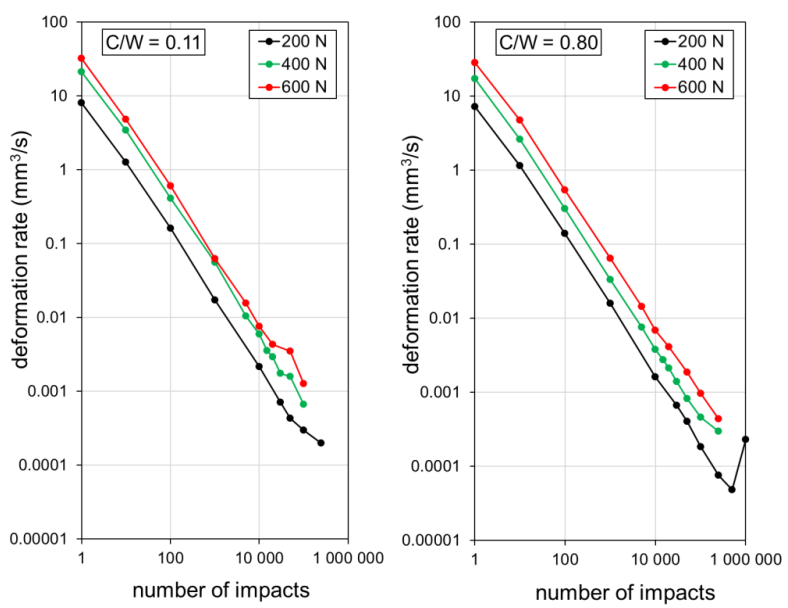

Figure 5. Deformation rate of the W-B-C coatings.

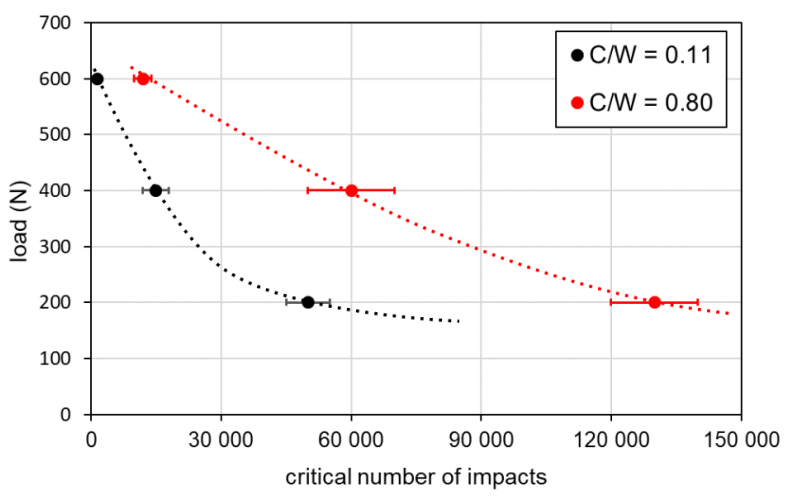

Figure 6. Woehler-like curves of the W-B-C coatings. Dotted lines were added as a visual guide.

modulus and therefore, a higher $\mathrm{H}^{3} / \mathrm{E}^{2}$ ratio that is related to resistance to plastic deformation and the coating toughness [10]. However, better impact resistance was observed in the case of the coating with the $\mathrm{C} / \mathrm{W}$ ratio of 0.80 . The main reason was different adhesion of the coatings to the HSS substrate. As was shown in Figure 3 the impact crater on the coating with the $\mathrm{C} / \mathrm{W}$ ratio of 0.11 created after 10 000 impacts with the load of $400 \mathrm{~N}$ exhibited cracking on its edge, while the impact crater on the coating with the $\mathrm{C} / \mathrm{W}$ ratio of 0.80 created after the same number of impacts at the same load exhibited an uninterrupted coated edge. Thus, the adhesion of the coating with the $\mathrm{C} / \mathrm{W}$ ratio of 0.80 was higher than the adhesion of the coating with the $\mathrm{C} / \mathrm{W}$ ratio of 0.11 . As the $\mathrm{H} / \mathrm{E}$ ratio was the same for both coatings, the adhesion of the studied coatings was the main parameters leading to better impact resistance.

\section{Conclusions}

Two W-B-C coatings with 30 at. $\%$ of boron and different $\mathrm{C} / \mathrm{W}$ ratios were deposited on HSS substrates and analyzed using the dynamic impact test. The impact loads of $200 \mathrm{~N}, 400 \mathrm{~N}$ and $600 \mathrm{~N}$ were used. The critical number of impacts determining coating failure was estimated using the loading curves, optical investigations and two novel parameters - impact resistance and deformation rate. The higher adhesion and of the coating to the HSS substrate led to the higher lifetime of the coating under repeated impact load.

\section{ACKNOWLEDGEMENTS}

This work was performed under the support of the projects LO1212 and LO1411 funded by Ministry of Education, Youth, and Sports of the Czech Republic, and project GA19-03899S funded by the Czech Science Foundation.

\section{REFERENCES}

[1] O. Knotek. A new technique for testing the impact load of thin films: the coating impact test. Surface and Coatings Technology 54-55:102-107, 1992. DOI:10.1016/0257-8972(92)90147-3

[2] K.-D. Bouzakis, N. Vidakis, T. Leyendecker, et al. Determination of the fatigue properties of multilayer PVD coatings on various substrates, based on the impact test and its FEM simulation. Thin Solid Films 308309:315-322, 1997. DOI:10.1016/s0040-6090(97)00561-0.

[3] K.-D. Bouzakis, A. Asimakopoulos, N. Michailidis, et al. The inclined impact test, an efficient method to characterize coatings' cohesion and adhesion properties. Thin Solid Films 469-470:254 - 262, 2004. Proceedings of the 31st International Conference on Metallurgical Coatings and Thin Films, DOI:10.1016/j.tsf.2004.08.093.

[4] P. Engel. Impact wear of multiplated electrical contacts. Wear 181-183:730-742, 1995. DOI:10.1016/0043-1648(94)07105-5

[5] A. Voevodin, R. Bantle, A. Matthews. Dynamic impact wear of $\mathrm{TiCxNy}$ and ti-DLC composite coatings. Wear 185(1-2):151-157, 1995. DOI:10.1016/0043-1648(95)06603-9 
[6] W. Heinke, A. Leyland, A. Matthews, et al. Evaluation of PVD nitride coatings, using impact, scratch and rockwell-c adhesion tests. Thin Solid Films 270(12):431-438, 1995. DOI:10.1016/0040-6090(95)06934-8

[7] J. Sobota, J. Grossman, V. Bursikova, et al. Evaluation of hardness, tribological behaviour and impact load of carbon-based hard composite coatings exposed to the influence of humidity. Diamond and Related Materials 20(4):596-599, 2011. DOI:10.1016/j.diamond.2011.01.011.

[8] K. Bobzin, L. Zhao, M. Öte, et al. Impact wear of an HVOF-sprayed cr 3 c 2 -NiCr coating. International Journal of Refractory Metals and Hard Materials 70:191-196, 2018. DOI:10.1016/j.ijrmhm.2017.10.011
[9] M. Alishahi, S. Mirzaei, P. Souček, et al. Evolution of structure and mechanical properties of hard yet fracture resistant w-b-c coatings with varying c/w ratio. Surface and Coatings Technology 340:103-111, 2018. DOI:10.1016/j.surfcoat.2018.02.054.

[10] J. Musil. Hard and superhard nanocomposite coatings. Surface and Coatings Technology 125(13):322-330, 2000. DOI:10.1016/s0257-8972(99)00586-1 